\title{
IESES E DISSERTACÕES EM ANTROPOLOGIA DEFENDIDAS NA UNIVERSIDADE FEDERAL DO RIO GRANDE DO SUL NO PERIODO DE JANEIRO A ABRIL DE 2001
}

\section{IESES}

\section{BRITES, Jurema}

\section{Orientadora: Claudia William Fonseca}

"Afeto, desigualdade e rebeldia - bastidores do serviso doméstico"

Trata-se de um estudo etnográfico sobre as relações de poder travadas entre empregadas domésticas e seus empregadores, baseada em trabalho de campo realizado no Espírito Santo entre 1996 e 1998. A partir de um quadro conceitual definido por Schellee Colen e James Scott, analisamos essas relações em termos de um sistema de reprodução estratificada, levando em conta tanto a desigualdade política e exploração quanto a funcionalidade dessa relação para ambas as partes. Através da observação participante, tivemos acesso aos códigos encobertos tanto das trabalhadoras quanto de seus empregadores, mostrando que uma mistura particular de afeto, desigualdade e rebeldia mantêm estas relações na sociedade brasileira.

\section{NETO, Francisco Pereira}

\section{Orientador: Ari Pedro Oro}

"Assistência social e caridade: religião, política e a construcão da solidariedade em Porto Alegre"

Este trabalho trata das iniciativas da sociedade que objetivam a construção de espaços de solidariedade e de assistência social na cidade de 
Porto Alegre. A prefeitura desta cidade detém a especificidade de, diferentemente da prática do poder público brasileiro em relação aos problemas sociais, investir no desenvolvimento de uma política social de caráter democrático, onde a sociedade é incentivada a participar das ações que levem à implementação de seus projetos políticos de combate às desigualdades sociais. A conseqüência dessa política é a relação do poder público com uma diversidade de agentes e instituições que tradicionalmente atuam no campo da assistência social, sendo grande parte deles de origem religiosa.

Assim, diante deste contexto, este trabalho procura destacar as relações entre as dimensões políticas e religiosas na definição de um espaço público que contempla diferentes lógicas acerca da realidade social e, conseqüentemente, diferentes formas de intervir na mesma. As relações de poder implicadas neste processo estão expressas em movimentos que expressam a ambigüidade produzida por diferentes visões da realidade social. Em termos mais específicos é possível vislumbrar as possibilidades e os limites da proposta de democratização da sociedade pautada na incorporação de valores políticos secularizados por uma população que, tradicionalmente, tem nas suas formas de expressão cultural religiosa um canal importante para ordenar suas relações (tanto públicas como privadas) na sociedade.

\section{RIETH, Flávia Silva}

\section{Orientadora: Ondina Fachel Leal}

"Pesquisa: sexo, amor e moralidade - iniciação na juventude de mulheres e homens, Pelotas (RS)"

Trata-se de uma investigação etnográfica com jovens mulheres e homens, na faixa dos 15 aos 19 anos, oriundos de camadas médias, em Pelotas, interior do Rio Grande do Sul, sobre amor, sexualidade e moralidade.

A análise versa sobre duas formas de associação entre os jovens: o ficar e o namorar, no que conformam um estilo jovem de sentir, pensar e agir. Em pauta, a discussão da noção de individuação da pessoa moderna no Brasil, focando a indicação sexual na juventude. Expõem-se os valores 
morais de gênero e a negociação das relações amorosas e sexuais no meio urbano contemporâneo.

Ressalta-se o "conflito romântico" nas trajetórias afetivo-sexuais das jovens, delineando a partir das escolhas entre ficar e namorar, de "conhecer a alma do outro" e "conhecer outras pessoas". Já para os rapazes, a sexualidade se coloca como uma aprendizagem técnica. Neste contexto de camadas médias do interior, tem-se que as jovens investem mais na sensibilidade, mas continuam se construindo relacionalmente, enquanto os rapazes se colocam como indivíduos, mas muito vulneráveis ao grupo de pares. 



\section{DISSERTACÕES}

\section{AMORIM, Cleides Antônio}

\section{Orientador: Ari Pedro Oro}

"Casa das Minas do Maranhão: vozes que "calam", o conflito que se estabelece"

Este texto antropológico trata da sociabilidade de uma comunidade religiosa e é resultado da experiência etnográfica desenvolvida junto às pessoas da Casa das Minas em São Luís/MA. Intenciona-se apreender os códigos simbólicos e os referenciais a partir dos quais os membros do terreiro negociam e repensam sua identidade cultural, através da observação dos rituais públicos e de entrevistas com seus principais conhecedores. O grupo declara que ser "mineiro" não é apenas participar dos cultos religiosos, mas é, antes de tudo, resultado da fusão do ethos e visão do mundo, da soma de um estilo de vida e de atitudes quotidianamente vivenciadas a partir de um conjunto normativo de regras e proibições.

\section{CANJÃO, Isanda Maria Falcão Orientadora: Cornélia Eckert}

"Bumba-meu-boi, o rito pede "passagem" em São Luís do Maranhão"

Nossa dissertação trata do ritual do bumba-meu-boi na cidade de São Luís, no Maranhão. Por estar o bumba-meu-boi situado no interior de uma prática social de tradição, comporta códigos e convenções simbólicas que estão fundamentadas num universo de relações de sentidos, num sistema simbólico que articula significados.

Portanto, como expressão de um universo simbólico, revela concepções de mundo, valores, crenças e sentimentos. Nesse contexto, nos situamos analisando o bumba-meu-boi como produção simbólica e enquanto experiência definidora de sentido dos indivíduos. 


\section{COCCARO, Luciane Moreau}

\section{Orientadora: Ceres Gomes Victora}

"Engordar na gravidez: estudo sobre as representacões das gestantes vinculadas ao DAG/ HCPA de Porto Alegre, acerca do ganho de peso corporal"

Esta dissertação de mestrado tem como foco de análise o estudo das representações de gestantes obesas ou com sobrepeso sobre o aumento de peso durante a gestação. As gestantes são pacientes do SUS (Sistema Único de Saúde) e participaram de um projeto de pesquisa junto ao Hospital de Clínicas de Porto Alegre sobre o controle do peso na gravidez. Foi utilizado o método etnográfico, com o uso das técnicas de observação participante, entrevistas semi-estruturadas, grupos focais e fotografias das gestantes. Este trabalho demonstrou que as gestantes pesquisadas têm basicamente preocupações com o aumento de peso por questões estéticas após a gravidez, diferente dos profissionais envolvidos no projeto que salientam os riscos para a saúde da mãe e do bebê, durante a gravidez.

Portanto, para as mulheres estudadas o aumento de peso não se configura como problema da gestação em si. A gravidez é um período no qual se espera que ocorram mudanças corporais e sociais.

\section{DORNELES, Edson Bertin}

\section{Orientador: Ruben George Oliven}

"Gramado, a producão e consumo de uma imagem de cidade européia no Brasil"

O objetivo desta dissertação consiste em investigar e analisar a construção histórica do turismo em Gramado (RS), observando os discursos dos moradores, seja em relatos através de entrevistas, seja em documentação coletada em pesquisa de campo. Analisa-se também a relação do processo histórico do turismo em Gramado no que se refere à produção de imagens de uma cidade "européia" direcionada, principalmente, à prática turística. Estas imagens produzidas são também avaliadas em relação ás falas de turistas sobre Gramado, o que permite pensar sobre o consumo de imagens sobre a cidade. 


\section{FERREIRA, Luciane Ouriques}

\section{Orientador: Oscar Alfredo Agüero}

"Maba-e Achy: a concepsão cosmológica da doença entre os Mbyá-Guarani num contexto de relações interétnicas"

A presente dissertação tem como objetivo compreender a concepção de doença presente no sistema médico tradicional Mbyá-Guarani. Para isso, parto do sistema cosmológico Mbyá, onde a noção de pessoa deste grupo étnico e suas relações com os outros seres habitantes de seu cosmos - humanos ou não - é central para o entendimento do conjunto das explicações tradicionais sobre as causas das doenças (etiologia); e também nas decisões relativas às escolhas dos tratamentos terapêuticos adequados à cada caso patológico. Por outro lado, pretende entender como o acirrado contato interétnico, estabelecido entre os Mbyá-Guarani e diversos segmentos da sociedade ocidental, pode tanto desencadear doenças como ser o motor de transformação do sistema médico tradicional que, frente a esse processo, desenvolve estratégias visando sua manutenção e sua atualização.

\section{GUIGOU, L. Nicolás}

\section{Orientador: Ari Pedro Oro}

"A Nação laica: religião civil e mito-práxis no Uruguai"

O projeto uruguaio de nação vinculou-se, desde seus inícios, diretamente a um radical processo de privatização da diversidade religiosa e cultural produzindo em troca, a partir do estado, uma religião civil, que marcou sua construção identitária.

A mencionada religião civil, conformada desde meados e finais do século XIX até aproximadamente a década dos ' 30 do século XX, baseouse em mitos e representações emblemáticas, cuja atualização pode ser detectada em grande parte até os nossos dias.

$\mathrm{Na}$ medida em que a escola pública teve um papel fundamental na produção e na difusão da mencionada religião civil, analisamos os textos 
de leitura utilizados nas escolas uruguaias, desde 1877 até a década dos '30, a fim de indagar os mitos e representações presentes nos textos, pedra fundamental da peculiar mito-práxis uruguaia e da "nação laica" uruguaia.

\section{MARTIN, Maria Eloisa}

\section{Orientador: Carlos Alberto Steil}

"Genuinamente correntina: um estudo antropológico da experiência católica na festa da Virgem de Itati"

Esta dissertação analisa a forma como as experiências de três atores da festa da Virgem de Itati, em seu santuário na província de Correntes, são atravessadas por um provincialismo de matriz correntina e decodificadas de forma variada por cada um desses atores.

A experiência dos moradores de Itati, os peregrinos e a igreja no marco da festa da Virgem, constitui um ponto onde particulariza-se, de forma diferente para cada um deles, uma experiência de catolicismo na Argentina como algo "genuinamente correntino". Ao mesmo tempo, são assinaladas as diferenças que se encontram no interior das experiências destes atores, que entendemos como sujeitos típico ideais.

\section{MÜLLER, Cíntia Beatriz}

\section{Orientadora: Claudia William Fonseca}

"Análise antropológica do Juizado Especial Criminal: uma etnografia da consciência legal"

O objeto desta dissertação se estabeleceu em torno do eixo de como as pessoas comuns, usuárias do juizado especial criminal em Porto Alegre e na cidade de Canoas, vêem a justiça em si e como o judiciário se relaciona com estas mesmas pessoas. Assim, agilizando certos conceitos da antropologia jurídica, trago situações de entrevista para explorar o que as 
pessoas buscam ao entrar em contato com "a lei", ao ir à delegacia e registrar uma "queixa", e de suas impressões sobre a ida ao fórum, para a audiência preliminar do juizado criminal. Tento apreender o modo como se dá a relação entre litigantes e julgadores no âmbito da audiência em si, do quanto os discursos podem ser estrategicamente dirigidos a partir da consciência legal dos envolvidos, com vistas a objetivos diversos: estabelecer um acordo ou conciliação, por parte do julgador; buscar a "justiça", por parte da vítima ou provar sua inocência, por parte do suposto autor do fato.

\section{NUMMER, Fernanda}

\section{Orientador: Ceres Gomes Victora}

"EM QAP: a experiência do curso de formação na construcãa de um saber ser soldado da Brigada Militar"

A realização do Curso Básico de Formação Policial Militar constitui um momento privilegiado para a análise do processo de pedagogização de um ethos e visão de mundo particular. $\mathrm{O}$ trabalho de campo que originou essa dissertação de origem etnográfica, foi realizado entre alunos soldados da Brigada Militar do Rio Grande do Sul, durante o curso de formação para as atividades de Policiamento Ostensivo, de novembro de 1999 a abril de 2000. Para a coleta de dados seguimos padrões da observação participante. A construção do objeto de estudo tem aporte teórico-metodológico no paradigma do embodiment (incorporamento). Baseados neste referencial de análise, procuramos discutir, inicialmente, algumas apreciações de visão e divisão que norteiam este espaço (relações com estranhos, princípios identitários e lógica masculina). Em seguida, , técnicas e estratégias pedagógicas adotadas para a inculcação de um saber ser soldado da Brigada Militar. Por fim, o fardamento como manifestação dos valores incorporados, pela hexis corporal que evoca e pelo processo de sujeição a uma ética moral idealizada de brigadiano. 


\section{OSÓRIO, Patrícia Silva}

\section{Orientador: Ruben George Oliven}

"Ai, que saudade da Lapa: o bar e a canção na (re)invenção da boemia em Brasília"

Esta dissertação trata de um pequeno grupo urbano da capital federal, que se utiliza da música como uma forma de expressão, construindo entre seus membros um tipo muito peculiar de sociabilidade. Em Brasília, há doze anos um grupo se reúne impreterivelmente às quarta-feiras em volta de uma grande mesa repleta de copos, garrafas de cerveja, vinho, uísque e água mineral. Sentadas à mesa, estas pessoas seguram violões, cavaquinhos, tamborins..., cantam e tocam diante de outras que se dispõem em mesas menores. O lugar da reunião é chamado Botequim das Quartas, e as pessoas sentadas em volta da mesa grande se nomeiam a Turma do Gambá. Os idealizadores do boteco vieram do Rio de Janeiro para Brasília por volta da década de setenta. Os participantes deste projeto inicial de construção do lugar se deslocaram para Brasília em virtude da transferência da sede da empresa na qual trabalhavam para a nova capital federal. No Rio, a sede de tal empresa ficava em um bairro percebido como o berço da malandragem, a Lapa. A Lapa com seus bares, personagens típicos e com todo o seu ambiente dito "boêmio", se faz muito presente no Botequim. A Lapa está no Hino e, principalmente, na memória do grupo. A intenção deste trabalho é refletir sobre este processo vivido por alguns membros da Turma do Gambá de "deixar" o Rio de Janeiro e com ele amigos, os bares, as serestas e a boemia, se aventurando num novo cenário urbano que a princípio representava tudo o que o Rio definitivamente não era. Mas foi neste ambiente aparentemente hostil e avesso ao prazer que algumas pessoas resolveram se unir, constituindo um grupo que em todas as noites de quarta-feira (re)inventa não só a cidade de onde vieram, como também a imagem do lugar onde atualmente vivem. 


\section{PEDDE, Valdir}

\section{Orientador: Ari Pedro Oro}

"Carismáticos luteranos e católicos: uma abordagem comparativa da performance dos rituais"

Esta dissertação procura compreender como a performance ritual contribui na elaboração e sustentação do ethos carismático em duas distintas instituições religiosas: a Igreja Evangélica de Confissão Luterana no Brasil e a Igreja Católica Apostólica Romana. Para isso, procuro verificar que recursos de performance são acionados no ritual de cada um destes grupos carismáticos. Centro a análise na compreensão de como os artifícios da performance agem sobre os participantes do ritual. A fim de alcançar este entendimento, são usados os pressupostos de teorias sobre ritual e performance.

Além de estudar o fenômeno supracitado nas duas igrejas separadamente, esta dissertação propõe uma análise comparativa entre as mesmas. O trabalho foi construído com base na pesquisa etnográfica realizada junto a comunidades carismáticas das instituições religiosas em referência, situadas em algumas cidades da Região Metropolitana de Porto Alegre.

\section{PEREIRA, Lenora Silveira}

\section{Orientador: Ari Pedro Oro}

"A discreta presença dos muçulmanos em Porto Alegre: uma análise antropológica das articulações de significados e da inserção do islamismo no pluralismo religioso local"

Esta dissertação versa sobre o islamismo em Porto Alegre. Considerando o islamismo uma opção religiosa que, não fazendo parte naturalmente da tradição cultural porto-alegrense e brasileira, no sentido de uma religião que se translada em uma nova sociedade e que inserindo-se no pluralismo religioso local, chama atenção quando adotada por etnias que não aquelas que lhes deram origem, indaga-se sobre a imagem que o 
islamismo detém na sociedade porto-alegrense. Centro a análise sobre os esforços de tradução da crença e valores, considerados como estratégias que os membros da religião islâmica em Porto Alegre põem em prática para encontrarem um espaço de legitimação e afirmação social na sociedade local.

Desta forma abordo as representações sociais dos não-muçulmanos em Porto Alegre sobre o islamismo e sobre os muçulmanos e, ao mesmo tempo, verifico as auto-representações dos muçulmanos de Porto Alegre acerca das representações do outro sobre si mesmos que indicam a presença de estereótipos, que remete ao estigma social, onde ao serem alvos de suspeitas os muçulmanos tentam romper, estabelecendo pontes entre seu sistema de crenças e a sociedade local.

\section{PICCOLO, Fernanda Delvalhas}

\section{Orientadora: Daniela Riva Knauth}

"Se deixar a droga levar...: um estudo sobre as trajetórias sociais de usuários de drogas em uma vila de Porto Alegre"

O presente estudo etnográfico analisa a trajetória de usuários de drogas, moradores do bairro Partenon, na cidade de Porto Alegre - Brasil. Buscou-se compreender qual o lugar que as drogas ocupam em suas trajetórias, as lógicas que orientam suas escolhas, os valores que estão em jogo, as redes sociais das quais participam e ainda apreender as representações e práticas sociais relacionadas ao uso de drogas e temas relacionados como a epidemia de Aids. 


\section{PINTO, Michele de Lavra}

\section{Orientador: Ruben George Oliven}

"Uma andorinha só não faz verão: um estudo antropológico sobre as práticas e motivacõoes do trabalho voluntário na Associação de Voluntários de Câncer de Mama do Hospital São Lucas em Porto Alegre"

Esta dissertação é o resultado de uma pesquisa etnográfica a respeito das práticas e motivações do trabalho voluntário na Associação de Voluntárias do Câncer de Mama do Hospital São Lucas em Porto Alegre, RS. O estudo analisa o que levou um grupo de mulheres a tornarem-se voluntárias do câncer de mama, e as relações e práticas que fazem parte de suas atividades dentro e fora do hospital. Este estudo contempla também aspectos que relacionam o trabalho voluntário ao terceiro setor e assinala algumas diferenças quanto ao surgimento desta atividade no Brasil e Estados Unidos.

\section{SCHWINGEL, Lúcio Roberto}

\section{Orientador: Oscar Alfredo Agüero}

"Chefia Kaingang num processo de relações interétnicas e de globalização - uma abordagem a partir da comunidade de Nonoai (Norte do Estado do Rio Grande do Sul)"

A presente dissertação trata da chefia Kaingang a partir da comunidade de Nonoai, cujo espaço de referência no contexto atual situa-se ao norte do Estado do Rio Grande do Sul.

Do ponto de vista teórico e metodológico, adota-se uma abordagem que compreende a realidade social e cultural em termos de um processo de construção entre distintos atores sociais, que manifestam e demarcam sua particularidade num contexto de relações interétnicas e de globalização.

$\mathrm{Na}$ abordagem temática, busca-se visualizar e caracterizar como os Kaingang se situam, se articulam e se afirmam a partir de sua organização social e política num contexto de relações que se estabelecem com a so- 
ciedade não indígena. Para tanto, leva-se em consideração os aspectos fundamentais da sua cosmologia, a trajetória de contato, que compreende a restrição e transformação de seu habitat, a as posições tomadas pela chefia Kaingang na situação atual, frente às demandas que se lhes apresentam no mundo contemporâneo.

\section{SILVA, Raimundo Nonato Pereira da}

\section{Orientador: Oscar Alfredo Agüero}

" 0 universo social dos indígenas no espaço urbano: identidade étnica na cidade de Manaus"

O presente trabalho procura contextualizar a partir do espaço urbano, aspectos da identidade étnica indígena na cidade de Manaus, Estado do Amazonas. Buscou-se com isso realizar uma leitura histórica, situando as etapas e os processos de urbanização pelos quais foram submetidos os índios, antes, durante e depois da colonização. O trabalho trata, assim, de observar a dimensão política que envolve as ações direcionadas à articulação e a mobilidade étnica na cidade e, finalmente, procura demonstrar como se dá a construção da territorialidade e da fronteira étnica no contexto urbano.

\section{SOARES, Mariana de Andrade}

\section{Orientador: Oscar Alfredo Agüero}

"A lição da Borboleta: processo de (re)construção da etnicidade indígena na região do Alto Jacuí no Rio Grande do Sul"

A presente dissertação propõe como objeto de pesquisa analisar o processo de (re) construção da etnicidade indígena da borboleta e o movimento reivindicativo de retomada das suas terras tradicionais nos municípios de Campos Borges, Espumoso e Salto do Jacuí no Rio Grande do Sul. 
A partir de uma perspectiva histórico-antropológica pretende-se analisar a questão da etnicidade dentro de uma dimensão política, que é reconstruída em um contexto situacional e relacional onde estão envolvidos diversos atores.

Tal problemática rompe com a representação do senso comum do que seja a categoria genérica de "índio", tanto no Rio Grande do Sul como no Brasil. Isto porque refere-se a compreensão de um universo que engloba diversas etnias e que atualmente está organizado reivindicando junto ao órgão indigenista oficial (FUNAI) a retomada de suas terras tradicionais e o reconhecimento da sua identidade culturalmente diferenciada.

\section{TOFFOLI, Gervásio}

\section{Orientador: Carlos Alberto Steil}

"Fazendo festa: uma análise antropológica das festas religiosas comunitárias em comunidades rurais no litoral norte do estado do RGS"

O presente trabalho tem por objetivo a descrição e análise do processo de re-construção das festas religiosas comunitárias no Litoral Norte do Estado do Rio Grande do Sul, tendo como foco de observação as festas do catolicismo em comunidades geográficas denominadas Morro do Forno e São Sebastião. Caracteriza-se por um estudo antropológico do fenômeno religioso, como uma forma de pensar a sociedade. As festas inserem-se como um sistema simbólico onde expressam e recriam o ethos e visão de mundo de um determinado grupo social, pela interação dos diferentes atores que compõem a cena.

De um lado, a obra pauta-se pelo estudo do processo histórico em que se define um modelo de festa pela sua particularidade religiosa na homenagem aos/as santos/as. Por outro lado, a análise volta-se para as festas como a instauração de um tempo favorável para delimitar e reinventar espaços na emergência de um novo modelo de comunidade, da mesma forma, um espaço propício para definir e confrontar os vários tempos de uma sociedade. 
As festas religiosas são aqui a expressão do protagonismo de atores que não apenas encenam uma peça já escrita, mas antes, a cada cena, manifestam-se co-autores de uma obra inacabada. Reinventam a religiosidade e a história, simplesmente "fazendo festa". 